\title{
Digital Instructional and Pedagogical Gaps in Mathematics Education during COVID-19: APOS Theory Based Laboratory Methodology in Higher Education
}

\author{
Leckson Mukavhi ${ }^{1}$, Deonarain Brijlall, ${ }^{2, *}$ \\ ${ }^{1}$ Department of Health Professions Education and Students Support Services, University of Zimbabwe, Harare, Mashonaland, \\ Zimbabwe \\ ${ }^{2}$ Department of Mathematics, Faculty of Applied Sciences, Durban University of Technology, Durban, KwaZulu-Natal, South Africa
}

Received February 9, 2021; Revised March 22, 2021; Accepted May 10, 2021

\section{Cite This Paper in the following Citation Styles}

(a): [1] Leckson Mukavhi, Deonarain Brijlall, "Digital Instructional and Pedagogical Gaps in Mathematics Education during COVID-19: APOS Theory Based Laboratory Methodology in Higher Education," Universal Journal of Educational Research, Vol. 9, No. 6, pp. 1134-1147, 2021. DOI: 10.13189/ujer.2021.090603.

(b): Leckson Mukavhi, Deonarain Brijlall (2021). Digital Instructional and Pedagogical Gaps in Mathematics Education during COVID-19: APOS Theory Based Laboratory Methodology in Higher Education. Universal Journal of Educational Research, 9(6), 1134-1147. DOI: 10.13189/ujer.2021.090603.

Copyright $\bigcirc 2021$ by authors, all rights reserved. Authors agree that this article remains permanently open access under the terms of the Creative Commons Attribution License 4.0 International License

\begin{abstract}
The COVID-19 pandemic globally transformed the face to face teaching and learning into digital online teaching and learning. The uptake and integration of digital technology in mathematics education have been gradual for many decades. However, the COVID-19 pandemic has reshaped the digital teaching and learning and made it an imperative and safe remote instruction and pedagogy of the day in mathematics education and education in general. We explored the uptake and use of virtual mathematics laboratory methodology for undergraduate Calculus teaching and learning as a remote instruction and pedagogy gap revealed during the COVID-19 infections prevention and containment period in Zimbabwe. The main objective of the study was to identify digital instructional and pedagogical gaps that existed in addressing students' mathematical misconceptions in Calculus learning in using the APOS theory and a virtual mathematics laboratory. Data was collected from 160 undergraduate students taking Calculus courses via APOS theory mediated digital mathematics laboratory for a semester. Results revealed that the undergraduate students who took the Calculus courses via the digital mathematics laboratory methodology performed better than those who used to take
\end{abstract}

the same courses using didactical approaches. This COVID-19 crisis ushered in digital teaching and learning experiences that clearly spelt out the existence of digital instructional and pedagogical gaps in mathematics education.

Keywords APOS Theory, COVID-19, Digital Teaching and Learning, Virtual Mathematics Laboratory

\section{Introduction}

The COVID-19 pandemic has largely affected greater parts of the world transforming totally the ways of lives of every humankind across the globe. The pandemic has proven to have taken tolls on global public health, business (trade and commerce), education, agriculture, social and political sectors with regards to their entities and systems. When Zimbabwe recorded its first COVID-19 confirmed case on 20 March 2020, measures for its infections prevention and containment such as total or partial lockdown series, social and physical distancing, closure of learning institutions, churches and shops, banning of public 
gatherings and transport and regular personal hygiene such as hand washing and cough etiquette were introduced and enforced until indefinite time. These measures affected the continuity of learning programs in the entire continuum of education. However, when the COVID-19 lockdown measures were eased, teaching and learning could not continue as face to face instruction and pedagogy. With this in mind we formulated the research question: How can different pedagogical strategies be implemented so as to cater for learning during the Covid-19 pandemic? We took this opportunity to implement the physical digitally well-resourced APOS theory mediated mathematics laboratory methodology to the teaching and learning of Calculus as virtual in response to COVID-19 prevention and containment compliance. This instructional and pedagogical experience revealed gaps in the digital teaching and learning which were concealed during the face to face classroom settings before the COVID-19 pandemic.

\section{Literature Review}

Although its novel, COVID-19's possible transmission modes were described by WHO as including contact, droplet, airborne, mother to child, formite, fecal-oral, bloodborne and zoonotic (animal to human). This nature of the spread of SARS-CoV-2 pathogen for COVID-19 rendered the greater majority of learning institutions as dangerous and breeding places for this human coronavirus [1] cited in [2].

[3] reported that by the end of March 2020, more than 180 countries had closed their learning institutions affecting 1.5 billion students constituting $84.7 \%$ of the global learners in general. [3] further reiterated that challenges existed in the global digital divide mostly affecting the middle to low-income countries as internet and mobile networks were not evenly accessed and access costs were not either affordable or sustainable to the majority of learners. [4] explained the distinctive circumstances of COVID-19 as the missing of face to face interaction and instruction in the education sector in general.

However, lots of opportunities were available that included paradigm shift from face to face instruction to digital and remote instruction and pedagogy as well as scaling up access and use of remote and virtual communication channels, online platforms and technology [5].

Furthermore, [6] advocated that with the advance in digital technology, the education sector shifted to digital and remote instruction as an adaptation and response to COVID-19 pandemic. Therefore, the COVID-19 pandemic is presenting challenges and opportunities for digital teaching and learning. Iwai [7] who researched on online learning during COVID-19 pandemic emphasized that students can gain or lose when learning environments become virtual. COVID-19 exposed huge digital gaps in how to access and utilize technology in pedagogically productive matter to facilitate teaching and learning [8]. On the other hand, [9] indicated that the instructional gaps existed in digital content generation, classification, scalability of technology to increase students reach and multimedia-channel sharing of resources especially in low resourced settings.

Studies on COVID-19 and digital learning are rapidly increasing. We subsequently decided to implement the APOS theory mediated mathematics laboratory methodology to undergraduate Calculus teaching and learning, work that had started before the pandemic, as virtual instructional and pedagogic path way for the progression of mathematics education courses in a remote and virtual mode using zoom meetings and online access to the virtual mathematics laboratory during this uncertain COVID-19 era. This provided some feasibility to pursue and recover undergraduate Calculus learning time during the social distancing period of the COVID-19 pandemic. Reimers [6] outlined a framework for providing guidelines to effective education response to COVID-19 pandemic.

[10] discussed the concept of mathematics laboratory. Mathematics Laboratory was viewed as a physical place with instructional materials that promote constructivist focused experiential learning. The instructional materials in the $21^{\text {st }}$ century mathematics laboratory include mathematical software, interactive 2D and 3D models, mathematical tools and technologies, interactive whiteboards, internet access, mobile applications and hand-held devices. However, [11] viewed mathematics laboratory as a methodology. Technology-based accessibility of mathematical knowledge among students in higher education has enormously changed [12] while the teaching strategies remained static. This scenario has been promoting the didactic transfer of mathematical knowledge [7] associated with poor learning outcomes.

[13] advocated that the teaching and learning of Calculus at undergraduate requires the use of a mathematics laboratory for students to appreciate the real-world applications of Calculus and to raise their interest in the discipline. Although several studies globally on the integration of mathematics laboratory and technology into mathematics education have been in existence, there are still different perspectives of its concept at institutional and international level [14]. However, [15, 16] asserted that there was need to scale up the integration of technology into mathematics education.

[17] investigated the effect of using mathematics laboratory in teaching on students' achievement in Junior Secondary School Mathematics in Nigeria and observed that the use of mathematics laboratory enhanced achievement in mathematics. Mathematics laboratory teaching was found out to be very effective on topical aspects of plane geometry and algebraic expressions. This 
study investigated on how mathematics educators can design and develop curriculum instructions for mathematics laboratory teaching and learning methodology using five randomly selected topics in Calculus courses at level one and two thereby giving structure to the guided learning and mathematical investigations.

On the other hand, [18] explained that the epistemological roots of the APOS theory are traced from Piaget's reflective abstraction as developed in [19] studies is based on mental structures or constructions [20-22] and [23] namely actions, processes, objects and schemas which the mathematics learners engage with mathematics concepts. The mental structures constitute the standard set of steps of mathematics concepts formation [24]. In order to clarify the tenets of APOS theory, we had to describe and examine them in the perspective of science and technology. [24] described action as being capable to execute the routine procedures bound to specific mental images.

[25] summarized the tenets of APOS when actions were described as routinized processes, encapsulated as objects and embedded as schema. The APOS theory however managed to describe what it takes for conceptual understanding in mathematics and how the learners of mathematics make mental constructions using specific pedagogical strategies. Several Calculus topics have so far been studied using APOS theory.

$[26,27]$ and [28] studied mental constructions of pre-service teachers when learning Calculus, fractions and matrix algebra in separate cases respectively. [29-31] studied the application of APOS theory on the students' understanding of limit of a function and integration; [23] studied mental structures and mechanisms and managed to characterize the processes as interiorization and coordination one hand and interiorization, coordination and reversal on the other hand. Weller et al [32] had also studied successfully and applied APOS on understanding the concepts of fractions. [33] studied the geometrical representations of two-variable functions in the three dimensional space using APOS theory while [16] also extended the application of APOS theory to Multivariate Calculus. Salgado and Trigueros [34] investigated classroom experiences of a modelling problem involving eigenvalues, eigenvectors and eigen spaces with successful object conception of difficult concepts; [35] studied the limit concept using APOS theory, [36] managed to study teachers' responses to questions on normal distribution using the APOS theory. [37] used APOS theory to study the students' understanding of the derivative concept. This rich literature evidence points out to the fact that indeed the APOS theory has a critical cognitive effort to the understanding of mental constructions and the related pedagogical strategies required to promote mental constructions in the converse.

\section{Materials and Methods}

A quasi-experiment on mathematics laboratory-based APOS and Bloom taxonomy instruction, in which two groups of Calculus students at the University of Zimbabwe underwent a differentiated teaching and learning approach for a semester in a virtual mode was used. The control group was taught using the traditional didactic pedagogy on a series of zoom meetings while the experimental group used the virtual APOS-Bloom Taxonomy mediated mathematics laboratory methodology accessed on an online link. The virtual mathematics laboratory was a digital ecosystem with a wide spectrum of mathematics e-resources. A pre-test covering the basic concepts of Calculus I was administered to check if there are any person confounds or if any participants have certain tendencies that are likely to affect the quality of association of their performance other than the intended treatment(laboratory mathematics education). The pre-test scores were used to randomly assign students to the quasi experimental and control groups. However, using the groups' average scores as cut-off scores and previous performance it was determined whether the student was assigned to the quasi-experimental group or control group. For ethical reasons and to eliminate_bias equal numbers of the below and above group average pre-test scores for each level were allocated to the quasi experimental and control groups with the previous performance as benchmarking measure to determine poor and excellent performance while maximizing internal and external validity. Two lecturers (L1 and L2) teaching Calculus I and Calculus II to level one and two students respectively participated in the study". Each lecturer had two groups characterized as experimental groups (EL1 and EL2) and control groups (CL1 and CL2) with 40 students in each group." The students were drawn from the current enrolments of Bachelor of Science Honours Mathematics, Bachelor of Science Special Honours Statistics, Bachelor of Education Science and Mathematics Education, and Bachelor of Science Honours Actuarial Science study programs from the Faculty of Science and Faculty of Education. Both experimental and control groups at each level were separately taught by the same lecturers and test scores for the pre-test and post- test were compared. We designed and developed the different laboratory based mathematics teaching and learning instructions for the experimental groups (EL1 and EL2) matching the levels appropriately. The instructional designs were designed and developed synchronously with the research work adopting APOS (Action-Process-Object-Schema) theory in order to enhance the infusion of technology, science and mathematics thinking processes while catering for ad hoc variations that may result. The two lecturers (L1 and L2) used the curriculum instructions to teach five randomly selected topics from the Calculus modules for a period of 16 weeks or a semester. The control groups (CL1 and CL2) 
were taught using the traditional didactic lectures on Zoom meetings. A theoretical analysis, genetic decomposition of the students' written exercise was conducted to give insights of digital instructional and pedagogical gaps as evidenced in the pre-test and post test scores comparisons while the technology acceptance model (TAM) was also used to measure the impact of the virtual mathematics laboratory methodology.

\section{Results}

Table 1a. Participants' Demographics

\begin{tabular}{ccc}
\hline Study Programs & Level I & Level II \\
\hline $\begin{array}{c}\text { Bachelor of Science Honours } \\
\text { Mathematics }\end{array}$ & 20 & 18 \\
$\begin{array}{c}\text { Bachelor of Science Special } \\
\text { Honours Statistics }\end{array}$ & 20 & 15 \\
$\begin{array}{c}\text { Bachelor of Education Science } \\
\text { and Mathematics Education } \\
\text { Bachelor of Science Honours } \\
\text { Actuarial Science }\end{array}$ & 15 & 20 \\
Total & 25 & 27 \\
Study Level & 80 & 80 \\
Male (M) & 55 & 48 \\
Female (F) & 25 & 32 \\
\hline Total & 80 & 80 \\
\hline
\end{tabular}

Table 1b. Participants Gender Characterization by Study Levels and Study Programs

\begin{tabular}{cccccc}
\hline & Level & I & \multicolumn{3}{c}{ Level II } \\
\hline Gender Disaggregation & M & F & M & F \\
\hline $\begin{array}{c}\text { Bachelor of Science Honours } \\
\text { Mathematics }\end{array}$ & 10 & 10 & 10 & 8 \\
\hline $\begin{array}{c}\text { Bachelor of Science Special Honours } \\
\text { Statistics }\end{array}$ & 12 & 8 & 10 & 5 \\
\hline $\begin{array}{c}\text { Bachelor of Education Science and } \\
\text { Mathematics Education }\end{array}$ & 13 & 2 & 14 & 6 \\
\hline $\begin{array}{c}\text { Bachelor of Science Honours Actuarial } \\
\text { Science }\end{array}$ & 20 & 5 & 14 & 13 \\
\hline
\end{tabular}

Note: Level I means students taking the Calculus I course in their first year of study program enrolled while Level II means students taking Calculus II course in their second year respectively.

The study included eighty (80) students at each level who were enrolled in four study programs as in Table 1a. There were fifty-five male students and twenty-five female students at Level I and forty-eight male students and thirty-two female students at Level II all from the Faculty of Science and Faculty of Education at the University of Zimbabwe. The gender disparity was treated as a confounder typical with STEM programs' enrolment in higher education globally. For the Level I group, 20 were enrolled for the Bachelor of Science Honours in Mathematics and Bachelor of Science Special Honours in Statistics apiece, 15 were in the Bachelor of Education in
Science and Mathematics Education and 25 were in the Bachelor of Science Honours in Statistics. On the other hand, the Level II group had 18 Bachelor of Science Honours in Mathematics, 15 Bachelor of Science Special Honours in Statistics, 20 Bachelor of Education in Science and Mathematics Education and 27 Bachelor of Science in Actuarial Science. This heterogeneity presented the necessary richness that was required in the understanding of mathematical thinking in Calculus I and Calculus II at the university level. However, the issue of gender disparity and other socio-cultural characteristics of the participants were regarded as cofounders whose effects did not misrepresent the impact of the virtual APOS-Bloom's Taxonomy mediated mathematics laboratory pedagogical strategy (intervention) on the learning outcomes from the student participants.

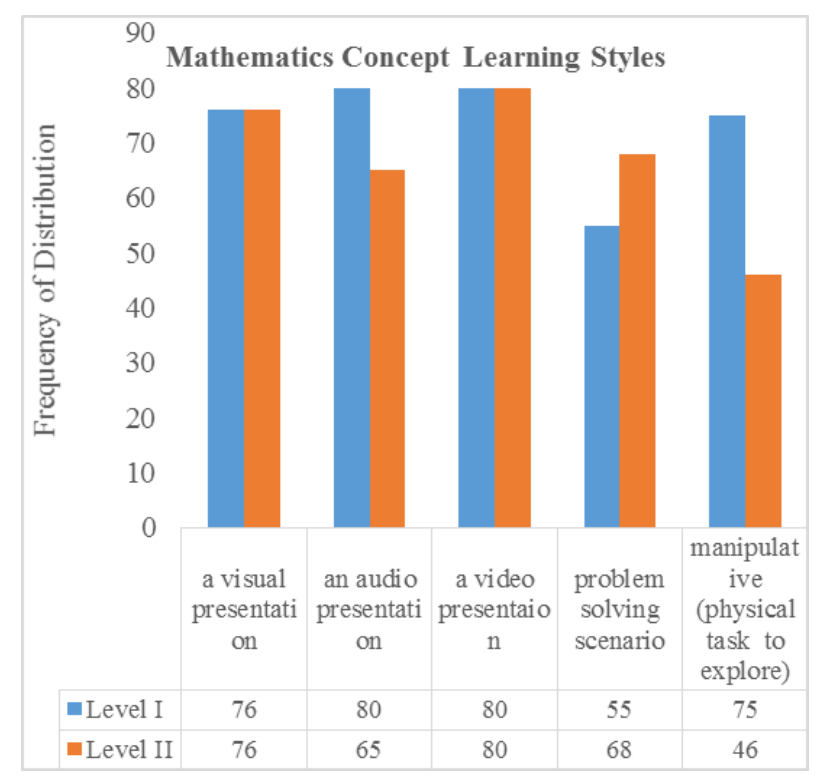

Figure 1. Participants' Mathematics Concept Learning Styles

When all the study participants at each level were asked to give their mathematics learning styles at the beginning of the study as in Figure 1, it emerged that at least $69 \%$ to $100 \%$ of the Level I participants preferred problem solving scenarios to audio or video presentations. On the other hand, at least $59 \%$ to $100 \%$ of the Level II participants preferred manipulative (physical task to explore) to video presentations. In the context of this study and perspectives of the constructivist philosophy that underpinned it, the knowledge and understanding of the study participants' mathematics learning styles at each level were fundamental for the application of the APOS theory on their mathematical thinking processes and the design of the pedagogical strategies (ACE cycle and DDMT), instructional strategies. It was therefore imperative for the digital instructional and pedagogical strategies to match the students' learning styles in order to obtain favourable learning outcomes. 


\section{Level I: Have you ever used technology in your Calculus Lessons to enhance your learning before?}

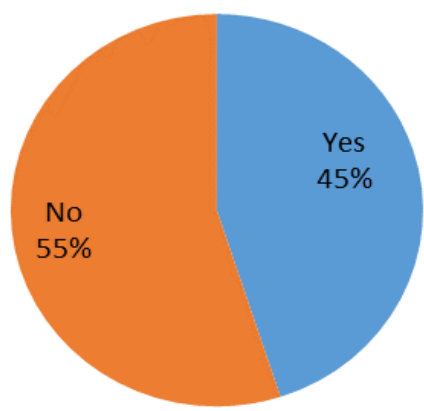

Figure 2. Technology usage in Undergraduate Mathematics Learning $[n=80]$

At level I, $45 \%$ of the study participants reported to have used technology in their Calculus Lessons while $55 \%$ had not used any technology before as shown in Figure 2. The technology usage gap was attributed to the high school-university transition as the undergraduates were recruited on merit from a variety of school categories.

The participants in the experimental group reported the nature of technology they had prior knowledge and skills of use before as revealed in the Figure 3 and Figure 4.

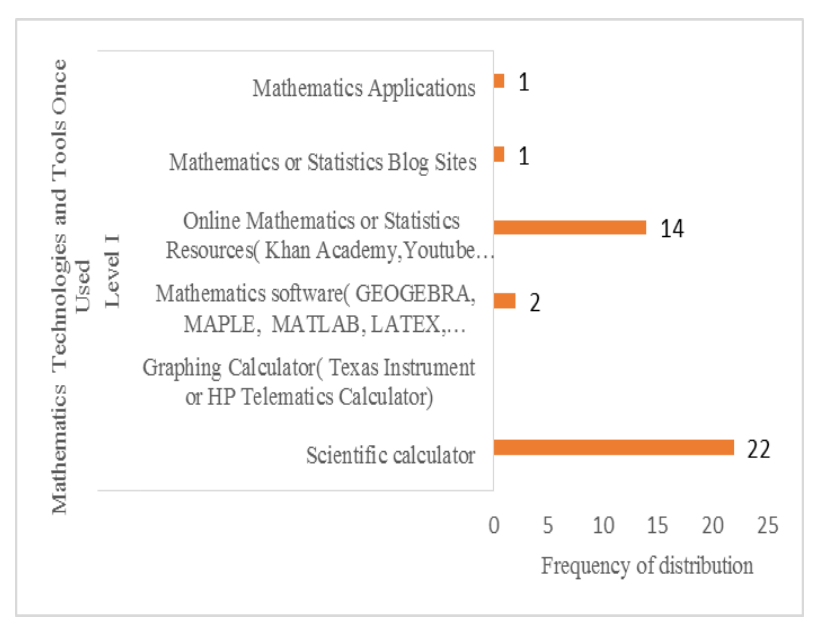

Figure 3. Mathematics Technologies and Tools Once Used by Participants $[n=40]$

The majority of participants were familiar with the scientific calculator which they used for numerical and hard to do manually calculations and a few online mathematics or statistics resources
Level II: Have ever you used technology in your Calculus Lessons to enhance your learning before?

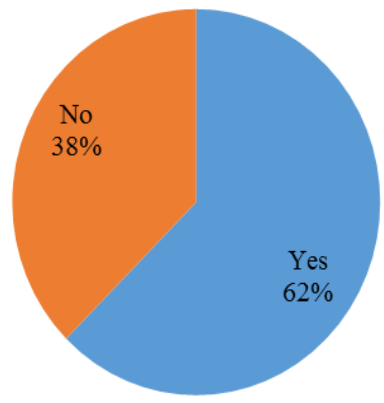

Figure 4. Technology usage in Undergraduate Mathematics Learning $[n=80]$

The majority of the Level II participants had a greater appreciation of a wide variety of technology but usage itself was reported to have been through remedial-based tutorials in the mathematics laboratory without any formal instruction during their Calculus I course. Sixty-two percent $(62 \%)$ acknowledged having used technology in their Calculus lectures to enhance learning process while thirty-eight percent $(38 \%)$ had not used any technology. The processes of appropriation of the technological tools were not formally taught by the lecturers as part of the curriculum.

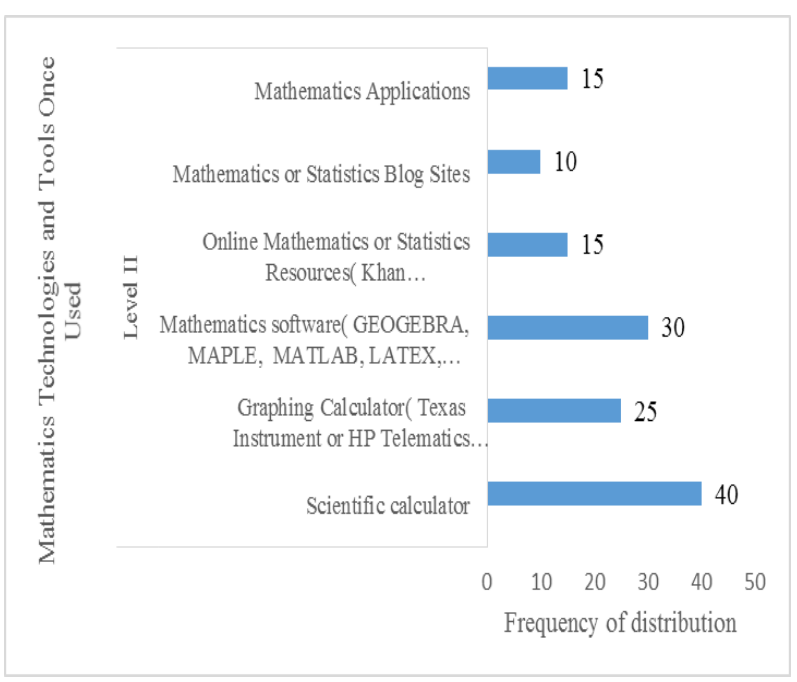

Figure 5. Mathematics Technologies and Tools Once Used by Participants $[n=40]$ 
The information on technology usage in Figure 5 was essential in the development and design of the teaching and learning instructions that incorporated the levels of appreciation of technology in the technology-rich mathematics laboratory intervention at each level to promote and study mathematical thinking processes in Calculus without any compromise of the participants' prior technological skills and knowledge. The heterogeneity of prior technology usage within each level-group (see figure 6) presented a motivational gap to adapt and integrate technology into the Calculus teaching and learning among the participants with experimental group being more enthusiastic to take part in the study. Brown and Green [38] as cited in [39] assert that learner and needs analysis should be conducted for any instructional and pedagogical intervention.

The participants in the experimental group at each level reported the various ways in which the technology would be used in the teaching and learning of Calculus at their respective levels prior to the implementation of the mathematics laboratory intervention.

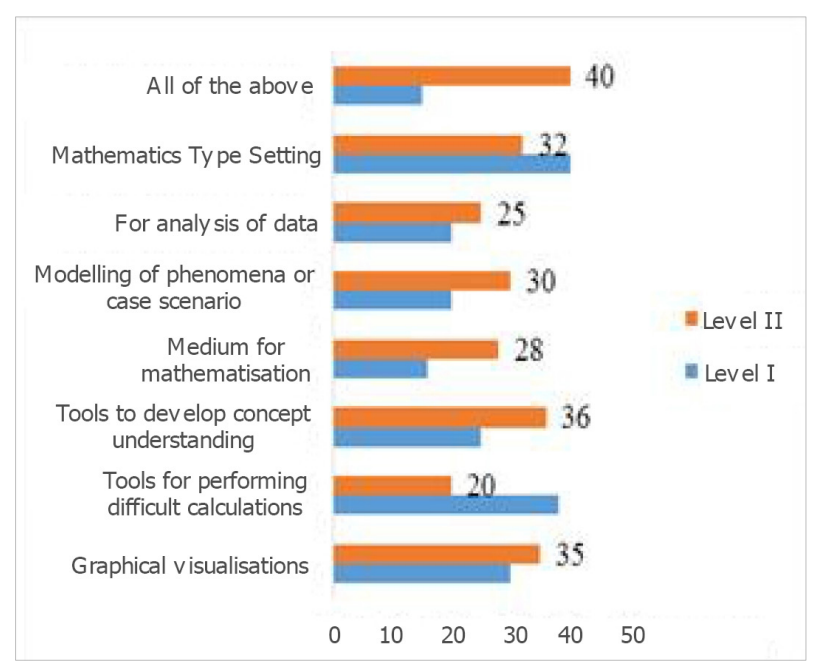

Figure 6. Possible Uses of Technology in the Learning of Calculus $[n=40]$

Among the participants of Level I, 38 out of 40 ) or (95\%) regarded technology as a tool for performing difficult (hard to do manually) calculations, seventy-five percent 30 out of 40 or $75 \%$ regarded technology as a means and medium for creating graphical visualizations, All $(100 \%)$ thoughts of technology as used for mathematics typesetting or all the possible suggested usage options while $63 \%$ said technology could be used for developing concept understanding. Among the participants of Level II, 36 out of 40 or $90 \%$ regarded technology as tools for developing concept understanding, analysis of data, 35 out of 40 or $88 \%$ considered technology a tool for graphical visualizations and 28 out of 40 or $70 \%$ regarded technology as a medium for mathematisation. Furthermore, the levels of confidence and degree of familiarity in using various mathematical software, tools and other artefacts in Calculus teaching and learning among the student participants were assessed.

Table 2. Students' Mathematics Technology and Tools Appropriation and Levels of Usage Confidence

\begin{tabular}{ccc}
\hline How did you learn about mathematics technologies? & $\begin{array}{c}\text { Level } \\
\text { I }\end{array}$ & $\begin{array}{c}\text { Level } \\
\text { II }\end{array}$ \\
\hline Trial and Error & $75 \%$ & $80 \%$ \\
\hline Friends & $40 \%$ & $65 \%$ \\
\hline Instructions for use & $20 \%$ & $50 \%$ \\
\hline Lecturers & $15 \%$ & $25 \%$ \\
\hline What is the level of confidence in using & & \\
\hline Scientific Calculators? & $100 \%$ & $100 \%$ \\
\hline Graphing Calculators & $40 \%$ & $60 \%$ \\
\hline Mathematical Software(CAS,GDS and others) & $40 \%$ & $75 \%$ \\
\hline Online Mathematics Resources & $50 \%$ & $60 \%$ \\
\hline Sample Size(n) & $\mathbf{8 0}$ & $\mathbf{8 0}$ \\
\hline
\end{tabular}

The statistics in Table 2 revealed that there were no formal processes of students' appropriation of the mathematical technologies and tools as the greater proportions of students reported having learnt by trial and error or through friends. This had impacted greatly on their levels of confidence in using the technologies and tools. The technology-rich mathematics laboratory was designed and developed with cross-cutting functions to cater for the various participants' perceptions, appropriation and confidence of technology usage in Calculus teaching and learning. The learning situation determines the instructional design and related instructional development analysis $[9,39]$ respectively.

Furthermore, this revealed that there are existing digital skills gaps among students and lecturers in higher education [40] that needed to be scaled up during the COVID-19 period.

[41] and [42] advocated for digital skills among students that included being able to find, curate and consolidate information in general.

On the other hand, the two lecturers were also assessed on their usage of the different means of virtual and remote instruction

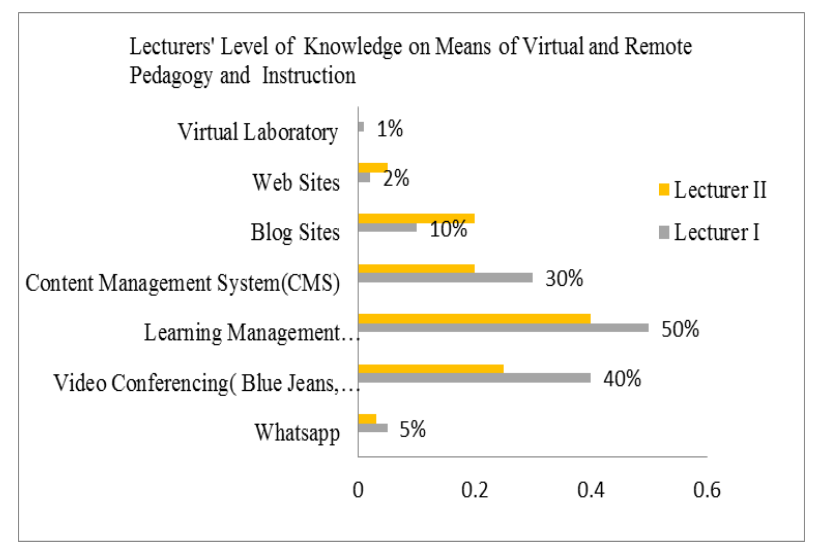

Figure 7. Means of Virtual and Remote Pedagogy and Instruction [n = 2] 
Out of the four (4) lecturers who were responsible for teaching Calculus course in the Mathematics Department; two (2) lecturers participated in the study (see Figure 7). While both lecturers had $40 \%$ and $50 \%$ knowledge of using the learning management systems for remote and virtual instruction respectively, it was revealed that other means of offering remote and virtual instruction in Calculus teaching such as the virtual laboratory, whatsapp platform, personal web sites, blog sites, content management systems and video conferencing were not fully known. Due to COVID-19 pandemic explorations with some of these means of virtual and remote instruction for teaching are now gradually gaining uptake.

Straumsheim, Jaschnik and Lederman[41] and Wise and Meyer[42] reiterated that faculty who have been experiencing challenges with the Learning Management Systems (LMS) functions for e-learning before the COVID-19 were required to survive the new digital academic life.

The variable set of items on the degree to which a participant Perceived the Ease of Use (PEU) of mathematics laboratory and technology were listed and coded (PEU1-PEU5) as follows:

PEU1: Learning to use mathematics applications and technologies was easy for me.

PEU2: I found it easy to get mathematics applications and technologies to do what I wanted to do manually.

PEU3: My interaction with mathematics applications and technologies was clear and understandable.

PEU4: It was easy for me to become skillful at using mathematics applications and technologies.

PEU5: I found mathematics applications and technologies easy to use.

A 5-point Likert Scale was used as "Strongly Disagree $=$ 1", "Disagree = 2", "Neutral = 3", "Agree = 4" and "Strong Agree $=5 "$ ". The variable set of five items had a Cronbach alpha, $\alpha=0.85$ and $p$-value $=0.618$ to show that the variable set had statistically significant internal consistency or reliability

Table 3a. Level I Perceived ease of use of mathematics applications and technologies $\left[\mathrm{n}_{1}=40\right]$

\begin{tabular}{cccccc}
\hline Item & $\begin{array}{c}\text { Frequency } \\
\text { [A-SA] }\end{array}$ & Mean & SD & Decision & $(\%)$ \\
\hline PEU1 & 40 & 5.3 & 1.8 & Accepted & 100 \\
PEU2 & 38 & 4.9 & 2.0 & Accepted & 95 \\
PEU3 & 40 & 4.6 & 1.7 & Accepted & 100 \\
PEU4 & 85 & 3.6 & 1.9 & Accepted & 95 \\
PEU5 & 40 & 4.9 & 1.9 & Accepted & 100 \\
GrandMean & & 4.7 & & Accepted & \\
\hline
\end{tabular}

*[A-SA $]$ means Agree to Strongly Agree.

All of the participants in Level I agreed or strongly agreed with the enlisted perceived ease of use of the mathematics laboratory and technology intervention used in this study. The results (see Table 3a) showed that 100\% agreed or strongly agreed with PEU1, PEU3 and PEU5 while $95 \%$ agreed or strongly agreed with PEU2 and PEU4. The overall response for the perceived ease of use variable set was accepted as the grand mean score was above 3 .

Similarly, the level II participants had their unique responses for the same perceived ease of use of the intervention.

Table 3b. Level II Perceived ease of use of mathematics applications and technologies $\left[\mathrm{n}_{2}=40\right]$

\begin{tabular}{cccccc}
\hline Item & $\begin{array}{c}\text { Frequency } \\
{[\text { A-SA }]}\end{array}$ & Mean & SD & Decision & $(\%)$ \\
\hline PEU1 & 40 & 4.5 & 1.6 & Accepted & 100 \\
PEU2 & 40 & 5.0 & 2.0 & Accepted & 100 \\
PEU3 & 40 & 4.6 & 1.7 & Accepted & 100 \\
PEU4 & 39 & 5.0 & 2.0 & Accepted & 97 \\
PEU5 & 40 & 5.0 & 2.0 & Accepted & 100 \\
GrandMean & & 4.8 & & Accepted & \\
\hline
\end{tabular}

*[A-SA $]$ means Agree to Strongly Agree.

In Table $3 \mathrm{~b}$ we observed that all of the participants $(100 \%)$ of the Level II participants agreed or strongly agreed with PEU1-PEU3 and PEU5 while 97\% agreed or strongly agreed with PEU4. Generally, the mathematics applications and technologies were perceived as easy to use by the participants in this category. In accordance with technology acceptance literature, when the perceive ease of use of any technology exists, it would promote its full integration as required by the constructivist teaching and learning that stimulates mathematics thinking under the study. Venkatesh et al. [32] and Moran et al. [40] as cited in [25] explained the technology performance expectancy is a fundamental predictor of the users' behavioural intentions in the technology acceptance model. Green [43] quoted in [44] asserts that the Technology Acceptance Model (TAM) is a tool for testing the users' acceptance of new technology. It was generally easy for the participants to use the mathematics applications and technologies in the mathematics laboratory.

The results resonated well with the fact that the perceived ease of use of technology is critical at an early stage of its integration or subsequent intention of use in the long-term [45, 32] as quoted in [25].

The variable set items of the Perceived Usefulness (PU) of the mathematics laboratory and technology in the teaching and learning of Calculus were also enumerated and coded for each level as follows:

PU1: Enable me to accomplish assessment tasks in Calculus more quickly.

PU2: Increase my retention of most of Calculus concepts.

PU3: Enhance my performance in Calculus.

PU4: Make the execution of the learning instructions easy.

PU5: Motivate me to like Calculus.

A 5-point Likert Scale was used as "Strongly Disagree = 
1", "Disagree =2", "Neutral = 3", "Agree = 4" and "Strong Agree $=5 "$. The variable set of five items of perceived usefulness of mathematics laboratory and technology had a statistically significant internal reliability (Cronbach alpha, $\alpha=0.91$ with $\mathrm{p}$-value $=0.62$ ).

Table 4a. Level I Perceived Usefulness of mathematics applications and technologies in learning $\left[n_{1}=40\right]$

\begin{tabular}{cccccc}
\hline Item & $\begin{array}{c}\text { Frequency } \\
{[\mathrm{A}-\mathrm{SA}]}\end{array}$ & Mean & $\mathrm{SD}$ & Decision & $(\%)$ \\
\hline PU1 & 35 & 4.7 & 1.8 & Accepted & 87 \\
PU2 & 38 & 4.8 & 1.9 & Accepted & 95 \\
PU3 & 40 & 4.6 & 1.6 & Accepted & 100 \\
PU4 & 40 & 4.2 & 1.9 & Accepted & 100 \\
PU5 & 40 & 4.7 & 1.8 & Accepted & 100 \\
GrandMean & & 4.6 & & Accepted & \\
\hline
\end{tabular}

*[A-*A-SA $]$ means Agree to Strongly Agree.

For Level I, all of the participants $(100 \%)$ reported the perceived usefulness of mathematics applications and technologies(PU3-PU5) applicable while $87 \%$ and $95 \%$ reported the applicability of PU1 and PU2 respectively (see Table 4a). However, the general views were that all the perceived usefulness variable set items of mathematics applications and technologies were applicable for this category of participants

Table 4b. Level II Perceived Usefulness of mathematics applications and technologies in learning Calculus $\left[\mathrm{n}_{2}=40\right]$

\begin{tabular}{cccccc}
\hline Item & $\begin{array}{c}\text { Frequency } \\
{[\text { A-SA }]}\end{array}$ & Mean & SD & Decision & $(\%)$ \\
\hline PU1 & 40 & 4.6 & 1.7 & Accepted & 100 \\
PU2 & 40 & 5.0 & 2.0 & Accepted & 100 \\
PU3 & 40 & 4.9 & 1.9 & Accepted & 100 \\
PU4 & 36 & 4.7 & 1.8 & Accepted & 90 \\
PU5 & 25 & 4.3 & 1.6 & Accepted & 62 \\
GrandMean & & 4.7 & & Accepted & \\
\hline
\end{tabular}

*[A-SA $]$ means Agree to Strongly Agree

In Table $4 \mathrm{~b}$ we noticed that all of the participants $(100 \%)$ in Level II agreed or strongly agreed that the usefulness of mathematics application and technologies in Calculus learning (PU1-PU3) applied while 90\% said PU4 was applicable and $62 \%$ reported the usefulness of PU5. However, $10 \%$ and $38 \%$ were neutral about this perception. It might be that the participants could have been deriving their motivation in Calculus from other sources other than the mathematics laboratory and technology intervention. Overall, the variable set items of perceived usefulness were applicable to this group.

Moran et al. [6] advocated that the perceived usefulness of a technological innovation is linked to its construct performance expectancy as cited in [38]. The results showed that the participants were satisfied with their expected performance of the mathematics applications and technologies in the mathematics laboratory intervention.
Therefore the integration of the technology-rich mathematics laboratory with the undergraduate mathematics learners at each level was possible. The virtual mathematics laboratory methodology partly leveraged on already existing digital content( open source educational resources) and lecturer-customized and contextualized mathematical content while at the same time the zoom meetings scaled up the technological intervention to reach out the huge students numbers in the study.



Figure 8. Students Knowledge on the use of Mathematics Laboratory in Calculus Learning $\left[n_{1}=40\right.$ and $\left.n_{2}=40\right]$

The Figure 8 revealed that 40 out of $40(100 \%)$ of both Level I and Level II participants knew tutorials as one of the mathematics laboratory activities. Ninety percent $(90 \%)$ of the Level I (36 out of 40) participants had some knowledge of mathematics experiment activities while 30 out of $40(75 \%)$ knew about simulations. Forty percent $(40 \%)$ of the Level I (10 out of 40) participants regarded remediation as a mathematics laboratory activity while $38 \%$ knew about problem solving projects.

Thirty percent $(30 \%)$ of the Level I (12 out of 40$)$ participants had some knowledge of mathematics typesetting as a mathematics laboratory activity. This pattern of responses from the Level I participants were attributed to their secondary and high school mathematics teaching and learning experiences and the types of the secondary and high schools they learnt from.

On the other hand, with the Level II 38 out of 40 (95\%) participants knew about mathematics experiments, 35 out of 40 or $88 \%$ had some knowledge of simulations, $50 \%$ (20 out of 40) knew about remediation while $45 \%$ (18 out of 40 ) knew about problem solving projects and $40 \%$ knew about mathematics typesetting. The Level II participants' pattern of responses resonated with their university mathematics laboratory pedagogical experiences which were largely influenced by lecturing, tutorials and remediation in a computer laboratory as a physical place rather a teaching and learning methodology. Generally, the Level II participants knew a wider variety of mathematics laboratory than their Level I counterparts. The participants' knowledge about the mathematics laboratory activities matched very well with the report by the Central Board of 
Secondary Education ('Guidelines for Mathematics Laboratory in Schools - Class IX') of 2005 that emphasized hands-on activities and projects as one of activities of the mathematics laboratory. Reggiani [39] and Duschl [25] also reiterated that hands-on activities, experimentations and projects with computer algebra systems were among the mathematics laboratory activities. Although the participants regarded the tutorials and remediation as mathematics laboratory activities, [47] regarded the mathematics laboratory as a teaching and learning methodology in itself in which a variety of constructivist strategies are used. However, Summit and Rickards [40] concurred with the constructivist approach to mathematics laboratory activities but with structuring (mathematics instruction) for conceptual understanding. Arnawa et al [47] in their study concluded that APOS theory instruction was significantly better than teacher-centred traditional lecture methodology due to the fact that mathematics ideas were discovered by students through fact finding in the mathematics laboratory activities among other benefits. There were no significant differences in the conceptualization of mathematics laboratory activities by the study participants between the study levels due to their use of the same laboratory environment at different time slots and being taught by lecturers with the same Technological Pedagogical Content Knowledge (TPCK).

The quantitative variables of interest for quantitative analysis in this study included the test scores from the control (CL1and CL2) and experimental groups (EL1 and EL2). The causal-effect relationships of the test scores from the control and experimental groups managed to measure the statistical extent of the impact of the study intervention on the students' mathematics learning outcomes.

Table 5. Post Test Scores Descriptive Statistics

\begin{tabular}{|c|c|c|c|}
\hline Group & & Level I & Level II \\
\hline Experimental & Maximum Score & 100 & 100 \\
\hline \multirow[t]{5}{*}{$\mathrm{n}=40$} & Minimum Score & 70 & 75 \\
\hline & Median Score & 90.5 & 90 \\
\hline & Mean Score & 88.7 & 89.4 \\
\hline & $\begin{array}{c}\text { Standard } \\
\text { Deviation }\end{array}$ & 8.9 & 6.9 \\
\hline & $\begin{array}{c}95 \% \text { Confidence } \\
\text { Interval }\end{array}$ & $(85.9 ; 91.6)$ & $(87.2 ; 91.6)$ \\
\hline Control & Maximum Score & 95 & 96 \\
\hline \multirow[t]{5}{*}{$\mathrm{n}=40$} & Minimum Score & 60 & 65 \\
\hline & Median Score & 84.5 & 80 \\
\hline & Mean Score & 81.5 & 80.5 \\
\hline & $\begin{array}{c}\text { Standard } \\
\text { Deviation }\end{array}$ & 10.4 & 9.2 \\
\hline & $\begin{array}{c}95 \% \text { Confidence } \\
\text { Interval }\end{array}$ & $(78.2 ; 84.8)$ & $(77.6 ; 83.5)$ \\
\hline
\end{tabular}

The mean score in Table 5, for the control group, was
81.45 with a standard deviation of 10.37 and 95\% confidence interval of $(78.2 ; 84.8)$ for the Level I participants while the mean score for the experimental group was 88.7 with a standard deviation of 8.89 and a $95 \%$ confidence interval of $(85.9 ; 91.6)$ for the same group with all values rounded to 1 decimal place.

With the Level II participants the mean score for the control group was 80.53 with a standard deviation of 9.22 and $95 \%$ confidence interval of $(77.6 ; 83.5)$ while the mean score for the experimental group was 89.40 with a standard deviation of 6.95 and a $95 \%$ confidence interval of (87.2; 91.6) for the same group with all values rounded to 2 decimal places.

The test scores revealed that the experimental groups(EL1 and EL2) had a higher mean scores and 95\% confidence intervals than those of the control groups at each level to suggest that the APOS-Blooms' Mathematics Instruction mediated Mathematics Laboratory intervention yield better learning outcomes than the traditional didactical instruction.

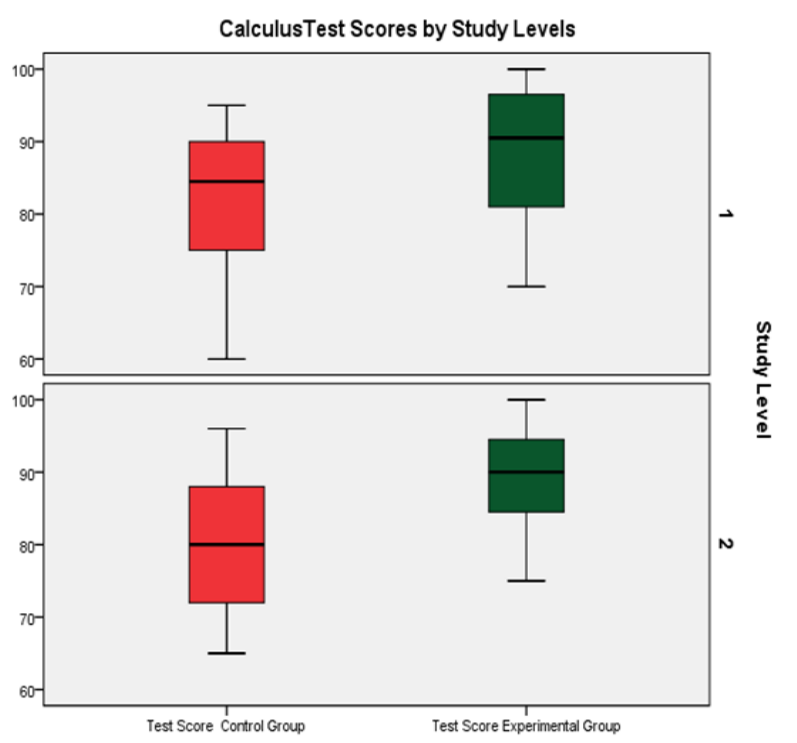

Figure 9. Post Test Scores Boxplots by Study Levels

A further scrutiny into the trend of the post test scores using the boxplots in Figure 9 summarized the interquartile ranges (IQRs) of the test scores for two groups under investigation and similarly revealed that the experimental group performed better than the control group at each level.

The implications were that the intervention was fundamentally useful at each level of Calculus teaching and learning at the undergraduate level. However, the single one-way analysis of variance would be able to determine how statistically significant the differences between the mean test scores of the experimental and control groups.

Furthermore, it was also imperative to compare the control and experimental groups in terms of the Pretest and Post Test scores by benchmarking the Pretest scores and make similar comparisons with the Post Test scores for each level. The effect size of the differences between the 
control and experimental groups was inspected using the boxplots factored by study programs and study levels.

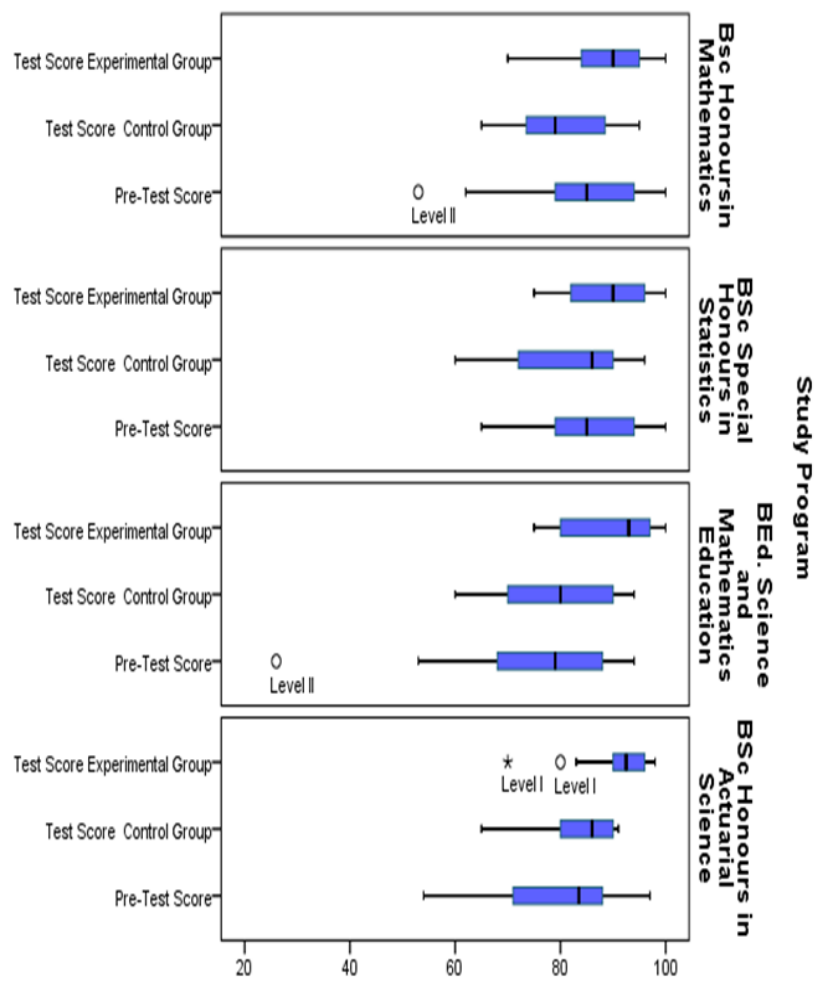

Figure 10. Post Test Scores Boxplots by Study Program and Study Level
In order to evaluate the comparative effectiveness of the intervention at each level and distinctive study programs, the post test scores boxplots that were factored by study level and study programs are illustrated in Figure 10. The boxplots for all the experimental groups per each program were shifted to the right towards a $100 \%$ to reflect improvement in performance. Although the performance of all the participants was improving at each level using the baseline of the pretest scores during the study, greater achievements were more in favour of the experimental group than control group. However, this shifting trend was distinctive for the Bachelor Honours in Actuarial Science at Level I and the rest of other programs at Level II. The effect size on the differences in groups' performance in the post test seemed to be study programs determined. Again, a single one-way analysis of variance or analysis of covariance was able to distinguish how statistical significant this trend was at each study program and study level.

In Table 6 the analysis of variance (ANOVA) was carried out for the combined post test scores of both levels combined to check if there were mean score differences between the control(CL1 and CL2) and experimental(EL1 and EL2) groups under investigation. The ANOVA results revealed that there was statistically significant mean score differences, $\mathrm{F}(1,158)=32.87$ with $\mathrm{p}$-value $=$ $4.87 \times 10^{-8}(\mathrm{p}<0.05)$ between the control and experimental groups of both levels combined.

Table 6. Analysis of Variance of Control and Experimental Groups' Post Tests

\begin{tabular}{|c|c|c|c|c|c|c|c|}
\hline \multicolumn{7}{|c|}{ ANOVA } & \multirow{3}{*}{$\begin{array}{r}\text { F Crit } \\
3.90\end{array}$} \\
\hline \multicolumn{2}{|c|}{ Source of Variations } & Sum of Squares & $\mathrm{df}$ & Mean Square & $\mathrm{F}$ & P-Value. & \\
\hline \multirow{3}{*}{$\begin{array}{c}\text { Test Score: } \\
\text { (Combined) } \\
\text { Control Group } \\
\text { Experimental Group }\end{array}$} & $\begin{array}{c}\text { Between } \\
\text { Groups }\end{array}$ & 2600.16 & 1 & 2600.16 & 32.87 & $4.87 \times 10^{-8}$ & \\
\hline & Within Groups & 12498.69 & 158 & 79.11 & & & \\
\hline & Total & 15098.84 & 159 & & & & \\
\hline \multirow{3}{*}{$\begin{array}{c}\text { Level I: } \\
\text { Control Group } \\
\text { Experimental Group }\end{array}$} & $\begin{array}{l}\text { Between } \\
\text { Groups }\end{array}$ & 1051.25 & 1 & 1051.250 & 11.28 & $1.22 \times 10^{-3}$ & 3.96 \\
\hline & Within Groups & 7271.95 & 78 & 93.23 & & & \\
\hline & Total & 8323.20 & 79 & & & & \\
\hline \multirow{3}{*}{$\begin{array}{c}\text { Level II: } \\
\text { Control Group } \\
\text { Experimental Group }\end{array}$} & $\begin{array}{c}\text { Between } \\
\text { Groups }\end{array}$ & 1575.31 & 1 & 1575.31 & 23.63 & $5.92 \times 10^{-6}$ & 3.96 \\
\hline & Within Groups & 5199.58 & 78 & 66.66 & & & \\
\hline & Total & 6774.89 & 79 & & & & \\
\hline
\end{tabular}


Furthermore, when the ANOVA was conducted for study levels separately, it again emerged there were some statistically significant mean score differences between the control and experimental groups for each level, $\mathrm{F}(1,78)=$ 11.28 with $p$-value $=1.22 \times 10^{-3}$ for Level I and $F(1,78)=$ 23.63 with $\mathrm{p}$-value $=5.92 \times 10^{-6}$ for Level II respectively. This implied that there were some significant differences in the performance of control and experimental groups under this study but the effect sizes that were later determined. The ANOVA with some factoring that was invoked brought up the following results.

The ANOVA factored by study levels showed that there were no statistically significant mean score differences in the post test scores between the control groups as evidenced by $\mathrm{F}(3,76)=0.187$ with the $\mathrm{p}$-value $=0.666$ $(p>0.05)$ and no significant within groups interaction at each level. Hence the study levels had no significant effect on the mean score differences of control groups' post test scores.

Likewise, there were also no statistically significant differences in the mean scores of the post test scores, $\mathrm{F}$ ( 3 , $76)=0.143$ with $p$-value $=0.706(p>0.05)$ between the experimental groups and no significant within group interactions at each study level. Therefore this suggested that study levels had no significant effect on the mean score differences of the experimental groups' post test scores as well.

However, when the effect sizes of study levels were considered, it emerged that study levels had an effect size of 0.018 that was small with p-value of 0.236 which was significant. Therefore, it meant that at both study levels there were significantly small mean score differences or equal improvements in the post tests of $62.8 \%$ across for both control and experimental groups, so the mean differences of the test scores were significantly small when considered at study levels within control and experimental groups under investigation.

The results of ANOVA factored by gender also indicated that there was no statistically significant mean score differences in the post test scores by gender, $\mathrm{F}(1,78)$ $=1.846$ with $p$-value $=0.178(\mathrm{p}>0.05)$ between the control groups and within groups interactions. Therefore, gender had no significant effect on mean score differences of the control groups' post test scores.

However, the effect size of gender in the post test scores of the control group, 0.628 was large with $p$-value $=0.00$

$(\mathrm{p}<0.05)$ so it was not significant.

On the contrary, there was statistically significant mean score differences in the post test scores by gender, $\mathrm{F}(1,78)$ $=6.348$ with $\mathrm{p}$-value $=0.014(\mathrm{p}<0.05)$ between the experimental groups and within experimental groups. Therefore, gender had significant effect on the mean score differences of the experimental groups' post test scores.

This means that although gender attributed to $6.5 \%$ improvement in the experimental groups' post test scores, the effect was not so significant as compared to the effect size due to the mathematics laboratory and technology in the experimental groups by itself. The effect size of experimental group of 0.656 was large with p-value $=$ 0.735. Thus the intervention alone caused $65.6 \%$ improvement in the experimental groups' test scores which was significantly large.

\section{Discussion}

In the main thrust of this study, we attempted to explore the digital instructional and pedagogical gaps in mathematics education during COVID-19 pandemic in Zimbabwe using the case of an APOS theory based virtual mathematics laboratory methodology in higher education settings. From the results above, the discussion points ranged from the understanding of the levels of the students and lecturers' digital artefacts and technologies acumen versus their mathematical learning styles and digital pedagogical and instructional dispositions respectively, how the integration and use of ICT advocated in the APOS theory fostered their mathematical knowledge construction and thinking, instrumental orchestration and how the demand for emergency and remote instruction in mathematics education due to the COVID-19 pandemic has managed to transition face to face pedagogies and pace up digital technologies and communication integration for utilization in the mathematics teaching and learning process. This sudden change in mathematics pedagogy and instruction has revealed a number of digital pedagogy and instruction gaps that existed in both mathematics educators and learners with regards to their digital skills, knowledge and perceptions and processes of appropriation.

The results confirmed the underscore of [48] that if mathematics learners use technological tools they can actively engage with the mathematics content for improved performance and strategic appropriation, especially in emergence situations as presented by COVID-19.

Typical of any other developing countries, Zimbabwe's digital communication and technology situation has not been developed to the level of that of the developed countries. This situation has affected digital inclusion and equity due to socioeconomic factors. In this study, some of the mathematical software, artefacts, technologies and tools that were available for use were not optimally utilized even though access was enhanced.

\section{Conclusions}

From our zoom meetings and the virtual mathematics laboratory methodology experiences to Calculus teaching and learning as a remote instruction measure to COVID-19 infections prevention and containment, it was concluded that the COVID-19 crisis provided an opportunity for 
mathematics educators to discover and exploit the digital instructional and pedagogical gaps that existed in mathematics education at tertiary level. The processes of appropriation of digital remote instruction and digital mathematics technologies, e-resources and tools to lecturers and students respectively should be formalized and integrated into the curriculum. Digital skills gaps still exist among students and lecturers in general.

Calculus teaching and learning using virtual mathematics laboratory can yield better students' learning outcomes than the traditional didactical methodologies. However, the access and uptake of digital resources for virtual and remote instruction depend on their perceived ease of use and perceived usefulness for their intended functions. The thrust during the COVID-19 pandemic was therefore the closing of digital teaching and learning gaps among the teachers and learners respectively.

\section{Acknowledgements}

We would like to extend our gratitude to the Durban University of Technology, South Africa and its entire staff for offering the student (author ${ }^{1}$ ) the Doctorate of Education study scholarship and unwavering studentship support, and the University of Zimbabwe for granting the student the permission to carry out the study with its various faculties.

\section{REFERENCES}

[1] Okigbo, E.C. and Osuafor, A.M. "Effect of Using Mathematics Laboratory teaching mathematics on the achievement of mathematics students", Educational Research and Review, vol.3 no.8, 2008.

[2] Maharaj, A. "An APOS analysis of natural science students' understanding of integration". REDIMAT - Journal of Research in Mathematics Education vol. 3 no.1, pp.53-72, 2014.

[3] David, R., Pellini, A., Jordan, K. and Phillips, T. "Education during the COVID-19 Crisis: Opportunities and Constraints of using EdTech in Low Income Countries", Education during the COVID-19 Crisis: Opportunities and Constraints of using EdTech in Low Income Countries, https://www.ukfiet.org/2020/education-during-the-covid-19crisis-opportunities-and-constraints-of-using-edtech-in-lowincome-countries/. ( Accsssed ,number 21, 2020)

[4] Brijlall, D.” Exploring the Pedagogical Content Knowledge for Teaching Probability in Middle School: A South African Case Study". International Journal of Educational Sciences, vol.7, no.3, 2014, DOI: 10.1080/09751122.2014.11890234.

[5] Agnoletto, R., \& Queiroz, V. "COVID-19 and the challenges in Education", Contemporary Educational Technology, vol.12 no.2, pp.269, 2020, .DOI: 10.30935/cedtech/7949. https:/www.researchgate.net/publication/340385425
(Accessed on November, 13, 2020).

[6] Moran, M., Hawkes, M., \& El-Gayar, O. "Tablet personal computer integration in higher education: Applying the unified theory of acceptance and use technology model to understand supporting factors". Educational Computing Research, vol.42 no.1, 2010, pp.79-101.http://dx.doi.org/10 .2190/EC.42.1.d.

[7] Dubinsky, E., \& Wilson, R. T. "High school students' understanding of the function concept". The Journal of Mathematics Behaviour, vol.32, pp.83-101, 2013.

[8] Caliskan, I. “A Case Study About Using Instructional Design Models In Science Education", Procedia-Social and Behavioral Sciences 116, pp.394-396, 2014. DOI:10.1016/j.sbspro.2014.01.228.

[9] Cobo, C. and Ciarrusta, I.S." Successful examples of scaling up teaching and learning in response to COVID-19". https://blogs.worldbank.org/education/successful-examplesscaling-teaching-and-learning-response-covid-19 (Accsessed August, 12, 2020.)

[10] Adenegan, K.E."Setting Mathematics Laboratory in Schools", .pp.1-6, Adeyemi College of Education, Nigeria. Unpublished paper, 2010.

[11] Maschietto, M. and Trouche, L. "Mathematics Learning and Tools from Theoretical, Historical and Practical Points of View: The Productive notion of Mathematics Laboratories". ZDM Mathematics Education, vol. 42 no.1, pp. 33-47., 2010. https://doi.org/10.1007/s11858-009-0215-3

[12] Webber, K., Nelson Laird, T., \& Brcka Lorenz, A Student and faculty members' engagement in undergraduate research. Research in Higher Education, vol. 54, no.2, pp.227-249, 2013. http://dx.doi.org/10.1007/s11162-012-9280-5.

[13] Basson, A., Krantz,S.G. and Thornton, B. "A New Kind of Instructional Mathematics Laboratory". Primus: Problems, Resources, and Issues in Mathematics Undergraduate Studies; vol.16, no.4, pp.332, 2006, DOI: 10.1080/10511970608984 156.

[14] Kashefi, H. "Mathematical Thinking in Multivariate Calculus Through Blended Learning". Universiti Teknologi Malaysia., Unpublished PhD Thesis, http://eprints.utm.my/i d/eprint/37808/5/HamidrezaKashefiPFP2012.pdf( Accessed on November, 19, 2020)

[15]Burns, M. 2019. "Background Paper Information and Communications Technologies and Secondary Education in Sub-Saharan Africa: Policies, Practices, Trends and Recommendations". DOI: 10.13140/RG.2.2.30769.74082.

[16] Eberly, M. B., Newton, S. E., and Wiggins, R. A. "The syllabus as a tool for student-centered learning", The Journal of General Education, vol. 50, pp.56-74, 2001. DOI: 10.1353/jge.2001.003.

[17] Maharaj, A. "A framework to gauge mathematical understanding: A case study on linear algebra concepts". International Journal of Education Science, vol.11 no.2, pp.144-153, 2015.

[18] Arnon, I., Cottrill, J., Dubinsky, E., Oktaç, A., Fuentes, S. R., and Trigueros, M., et al. "APOS theory: A framework for research and curriculum development in mathematics Education”, “APOS Theory: A Framework for Research and 
Curriculum Development in Mathematics Education", $\left(1^{\text {st }} \mathrm{ed}\right)$, Springer Science\& Business Media, 2015,pp. 1-91.

[19] Cross, K. P." Classroom Research: Implementing the Scholarship of Teaching." New directions for teaching \& learning, vol.1998 no.75, pp.5-12, 2002. https://doi.org/10.1 $002 / \mathrm{tl} .7501$.

[20] Iwai, Y. "Online Learning during the COVID-19 Pandemic: What do we gain and what do we lose when classrooms go virtual?" Scientific American.https://blogs.scientificamerica n.com/observations/online-learning-during-the-covid-19-pa ndemic (Accessed on March, 24, 2020).

[21] Kashefi, H., Ismail, Z. \& Yusof, Y. M. "Obstacles in the Learning of Two-variable Functions through Mathematical Thinking Approach". Procedia Social and Behavioral Sciences vol. 8, pp.173-180, 2010, DOI: 10. .1016/j.sbspro.2010.12.024.

[22] Kriek,J. and Stols, G. "Teachers' beliefs and their intention to use interactive simulations in their classrooms". South African Journal of Education, vol.30, pp. 439-456, 2010.

[23] Sintema, E. J. "Effect of COVID-19 on the Performance of Grade 12 Students: Implications for STEM Education". Eurasia Journal of Mathematics, Science and Technology Education, vol.16 no.7, em1851, 2020, https://doi.org/10.29 333/ejmste/7893.

[24] Bennet, C. "The Logic of Learning. Axiomathes" vol.29, pp. 173-187, 2019, https://doi.org/10.1007/s10516-018-9394-2.

[25] Duschl, R.A. "The HS Lab Experience: Reconsidering the Role of Evidence, Explanation and the Language of Science". Rutgers University. Unpublished Paper, 2010, https://www.i nformalscience.org/sites/default/files/R_Duschl_Final_Pape r.pdf.

[26] Brijlall, D.” Exploring the Pedagogical Content Knowledge for Teaching Probability in Middle School: A South African Case Study". International Journal of Educational Sciences, vol.7 no.3., 2014, DOI: 10.1080/09751122.2014.11890234

[27] Brijlall D, Maharaj A. "Exploring support strategies for high school mathematics teachers from underachieving schools". International Journal of Educational Sciences, vol.7no.1, pp. 99-107, 2014. DOI: 10.1080/09751122.2014.11890173

[28] Brijlall,D. and Ndlovu, Z. ." Exploring high school learners' mental constructions during the solving of optimization". South African Journal of Education, vol.33, no.2, pp.157-171, 2013, DOI: 10.15700/saje.v33n2a679.

[29] Maharaj, A. “An APOS Analysis of Students' Understanding of the Concept of a Limit of a Function". Pythagoras, vol.71, no.6, pp.41-52. 2010, https://doi.org/10.4102/pythagoras.v0i 71.6 .

[30] Maharaj, A. "An APOS Analysis of natural science students' understanding of the derivatives", South African Journal of Education, vol.33 no.1, pp.1-19, 2013. https://doi.org/10.15 700/saje.v33n1a458

[31] Maharaj, A. "An APOS analysis of natural science students' understanding of integration". REDIMAT - Journal of Research in Mathematics Education vol. 3 no.1, pp.53-72, 2014.

[32] Weller, K., Arnon, I., \& Dubinsky, E. "Preservice teachers' understanding of the relation between a fraction or interger and its decimal expansion". Canadian Journal of science, Mathematics and Technology Education, vol. 9 no. 1, pp. $5-28,2009$

[33] Trigueros-Gaisman, M. and Martínez-Planell, R. "On students' understanding of Riemann sums of integrals of functions of two variables". INDRUM 2018, INDRUM Network, University of Agder, Kristiansand, Norway, April 2018, Hal-01849951.

[34] Salgado, H. and Trigueros, M. "Teaching Eigenvalues and Eigenvectors using models and APOS theory". Journal of Mathematical Behavior vol.39, 2015, pp.100-120. Elsevier.

[35] Cottrill, J., Dubinsky, E., Nichols, D., Schwingendorf, K., Thomas,K. and Vidakovic, D.. "Understanding the Limit Concept: Beginning with a Coordinated Process Schema." Journal of Mathematical Behavior 15, pp.167-192, 1996.

[36] Bansilal., S."Using an APOS framework to understand Teachers' responses to questions on the normal distribution". Statistics Education Research Journal, vol.13, no.2, pp. 42-57, 2014.

[37] Sánchez-Matamoros, G., Fernández, C., \& Llinares, S. "Developing pre-service teachers' noticing of students' understanding of the derivative concept". International Journal of Science and Mathematics Education. vol.13 no.6, pp.1305-1329, 2015.https://doi.org/10.1007/s10763-014-95 44-y.

[38] Brown, A., Green, T. D. "The essentials of instructional design: Connecting fundamental principles with process and practice". Boston: Allyn \& Bacon, 2011.

[39] Reggiani, M." Mathematics Laboratory activities with Derive: Examples of approaches to Algebra". University of Pavia, 2005.

[40] Summit, R. and Rickards, T.” A constructivist Approach to Laboratory Mathematics Classes." Curtin University, 2013.

[41] Straumsheim, C., Jaschik, S., \& Lederman, D.” 2015 Survey of faculty attitudes on technology (Rep.)." Gallup and Inside Higher Ed. from https://www.insidehighered.com/audio/201 5/11/12/2015-survey-faculty-attitudes-technology, (Accessed on 13 November,2020

[42] Wise, S. and Meyer, M. "Teaching and Learning with Technology", 2011, http://www.colorado.edu/assett/sites/de fault/files/attached-files/final-fac-survey-full-report.pdf. (Accessed on December, 2, 2020)

[43] Green, IFR. "The emancipatory potential of a new information system and its effect on technology acceptance". Unpublished $\mathrm{PhD}$ dissertation. Pretoria: University of Pretoria, 2005

[44] Morrison, D. "Higher Education's Skills Gaps: Faculty and Students".

https://onlinelearninginsights.wordpress.com/2016/11/19/hi gher-eds-digital-skills-gap-faculty-students/ (Accessed on August, 12, 2020).

[45] Niess, M. L. "Preparing teachers to teach Mathematics with technology". Contemporary Issues in Technology and Teacher Education, vol.6 no.2, 2006. http://www.citejournal .org/vol6/ iss2/mathematics/article1.cfm.

[46] Maschietto, M. "Teachers, students and resources in mathematics laboratory". $12^{\text {th }}$ International Congress on 
Mathematical Education", COEX, Seoul, Korea, (8 July - 15 July), 2012.

[47] Arnawa, I.M., Sumarno, U., Kartasasmita, B and Baskoro, E.T. "Applying the APOS theory to improve students' ability to prove in Elementary Abstract Algebra". Journal of
Indonesian Mathematics Society, MIHMI, vol.13 no.1, pp.133-148, 2007, DOI: 10.22342/jims.13.1.80.133-148.

[48] Common Core State Standards Initiative Report, Council of Chief State School Officers (CCSSO) and the National Governors, 2010. 